\title{
Increased Exercise Effort after Artificially-Induced Stress: Laboratory-Based Evidence for the Catharsis Theory of Stress
}

\author{
Attila Szabo, Eliza Tóth, Lili Kósa, Ádám Laki, Ferenc Ihász \\ ELTE Eötvös Loránd University, Budapest, Hungary
}

\begin{abstract}
Background. Evolution prepared humans to deal with physical challenges. Today, people encounter psychosocial stress more than physical stress. However, the physiological response to the contemporary forms of stress is still preserved as the biological evolution's vestigial heritage. This laboratory investigation aimed to determine whether brief mental stress triggers greater innate (instinctual) effort to 'let off steam' than a non-challenging control condition.

Method. Using a counterbalanced within-participants laboratory design, 29 young men walked/jogged at voluntary (self-paced) effort after two conditions: a) artificially-induced mental stress comprised by the Stroop Color-Word Task, which lasted for five minutes, and b) a control session, also lasting for five minutes, in which the participants watched a video depicting the world's ten tallest buildings.

Results. The increased arousal after mental stress was carried over into the walk or jog period, and participants worked harder, but they did not perceive exerting greater effort in contrast to the control condition.

Conclusions. These results suggest that a 'flight or fight' response to psychosocial stress is manifested in the form of subliminal catharsis. While larger-scale studies with more impactful stressors are needed, these preliminary results support the catharsis theory. They might open new research avenues to provide people more physical opportunities for letting off steam before the necessity of treatment with chemical substances or other behavioral therapies.
\end{abstract}

Keywords: cognitive stress, exercise, mental stress, flight or fight, physical activity, psychosocial stress.

\section{INTRODUCTION}

$\mathrm{T}$ The physiological response to psychosocial stress was explained via three theories: a) nonspecific, b) vestigial, and c) borrowed (Péronnet \& Szabo, 1993). The first theory suggests that human response to psychosocial stress is identical for all stressors and generalized to the whole body. This theory has been refuted (e.g., Péronnet \& Szabo, 1993; Sosnowski, Nurzynska, $\&$ Polec, 1991). The vestigial theory postulates that the somatic response to psychosocial stress is of evolutionary origin from the ancestors who encountered primarily physical forms of stress. It had adaptive value in their survival, so it emerged through natural selection. The response is still preserved, and many individuals experience it as a reaction (i.e., sweating of the palms) to psychosocial stress (Péronnet \& Szabo, 1993). The third theory postulates that contemporary humans borrow a vestigial response, one of which is the well-known 'flight or fight' reaction (Cannon, 1915) when facing psychosocial stress. Cannon proposed that in a heightened state of arousal, the sympathetic system stimulates adrenaline release to mobilize the organism for a stress response characterized by a sudden burst of energy that initiates the (physical) flight or fight response.

However, a physical response to psychosocial stress is most often inappropriate today. Thus, modern humans must inhibit a 'natural' response, while the evolutionary period was too short to prepare them for contemporary life's typical psychosocial stress. However, inhibition of the physical stress-response results in neuroendocrine toxicity that leads to disease (Miller \& O'Callaghan, 
2002). Therefore, while the naturally evolved stress response played a protective role in the ancestors' survival, it has significant health-damaging consequences to the 'civilized' humans (McEwen, 1998) because, in contemporary societies, they can no longer use the physical means of coping.

The burst of surplus energy, resulting from stress, must be released by other than physically aggressive means. Exerted physical effort via physical exercise is one means through which an individual can "let off steam" and, therefore, manifest a cathartic response (Huđin, Glavaš, \& Pandžić, 2020) to experience psychological relief. It is not surprising then that recently exercise addiction, associated with coping with stress (Egorov \& Szabo, 2013), was also linked to catharsis (Walter \& Heinen, 2019). Catharsis can be conceptualized as an index of blocked or incomplete emotion and as a way of changing one's awareness or actions (Steckley, 2018). Changes in physical effort, or exercise behavior after stress, could reflect both conscious and subconscious internal regulation, mirroring a cathartic response.

Szabo and Tsang (2003) suggested that the vestigial stress-response, preparing one for 'fight or flight' during psychosocial stress, might trigger an instinctual urge to let off steam. This urge surfaces in a cathartic drive to get rid of physical energy. The authors examined 40 males in a betweenparticipants research design testing an experimental and a control group. The former watched 30 explicit war images (a form of passive stress), while the control group watched 30 neutral images of urban architecture. After the respective interventions, both groups were asked to cycle on an ergometer at a self-selected pace for $20 \mathrm{~min}$. The results revealed that the experimental group chose to exercise with $25 \%$ higher intensity than the control group, while no between-group differences were observed in the perceived exertion. Szabo and Tsang (2003) interpreted their findings as evidence for the catharsis theory. However, a between-participants design may not be adequate for studying the catharsis hypothesis unless it can be ensured that the two groups possess identical skills. A withinparticipant cross-over design is more appropriate in addressing this research issue.

In this laboratory work, we replicated and expanded the study of Szabo and Tsang (2003) by using a cross-over within-participants design and a relatively mild (ethically feasible) stressor comprised by the Stroop Color-Word Task (Stroop,
1935). However, a five-minute exposure to this frequently employed laboratory stressor may be very challenging (Boutcher \& Boutcher, 2006). Further, the here-employed stressor required active coping, which is in contrast to Szabo and Tsang, who presented explicit war images to their participants, which triggered passive coping. We also reduced the exercise duration from 20 to five minutes because a cathartic response could be expected the surface in the early period following the stress-exposure (Brown, Szabo, \& Seraganian, 1988). Finally, in contrast to Szabo and Tsang, in this study, we used a treadmill that allowed participants to walk, jog or run, to provide a broader range of selectable movement repertoire after the interventions. Like Szabo and Tsang, we also posited that the residual effects of stress would surface in more physical effort or harder work compared to a control condition.

\section{METHODS}

Participants. University students enrolled in extramural physical activities were recruited through a campus-wide call to participate in the study in exchange for the measurement of their percent body fat, body mass index (BMI), and muscle mass. Using a priori sample size calculation, by employing the $G^{*}$ Power (v. 3.1) software (Faul et al., 2009), the minimum required sample size for the study (based on repeated measures analyses of variance [RMANOVA], within factors) was $\mathrm{n}=26$. This number was based on a medium effect size $(f)=.25, \alpha=.05, r=.50$, and power $(1-\beta)=.85$. Of the 30 men who volunteered, 29 completed the study. Their age was $21.90( \pm S D=1.88)$ years and BMI was $24.38( \pm S D=12.61)$. The work received ethical clearance from the university's Research Ethics Committee (Certificate No. 2019/185). It conformed to the World Medical Association Declaration of Helsinki Ethical Principles for Medical Research Involving Human Subjects (WMA, 2019).

Materials. The Stroop Color-Word Task (Stroop, 1935), in which color words are presented in incongruent colors (i.e., the word 'green' displayed in red), was used to elicit mental stress for five minutes. Its stress-inducing potential was shown in several studies (Karthikeyan et al., 2011). The task of the participant is to ignore the semantic content of the word and only name the color in which the serially displayed words appear on the screen. In 


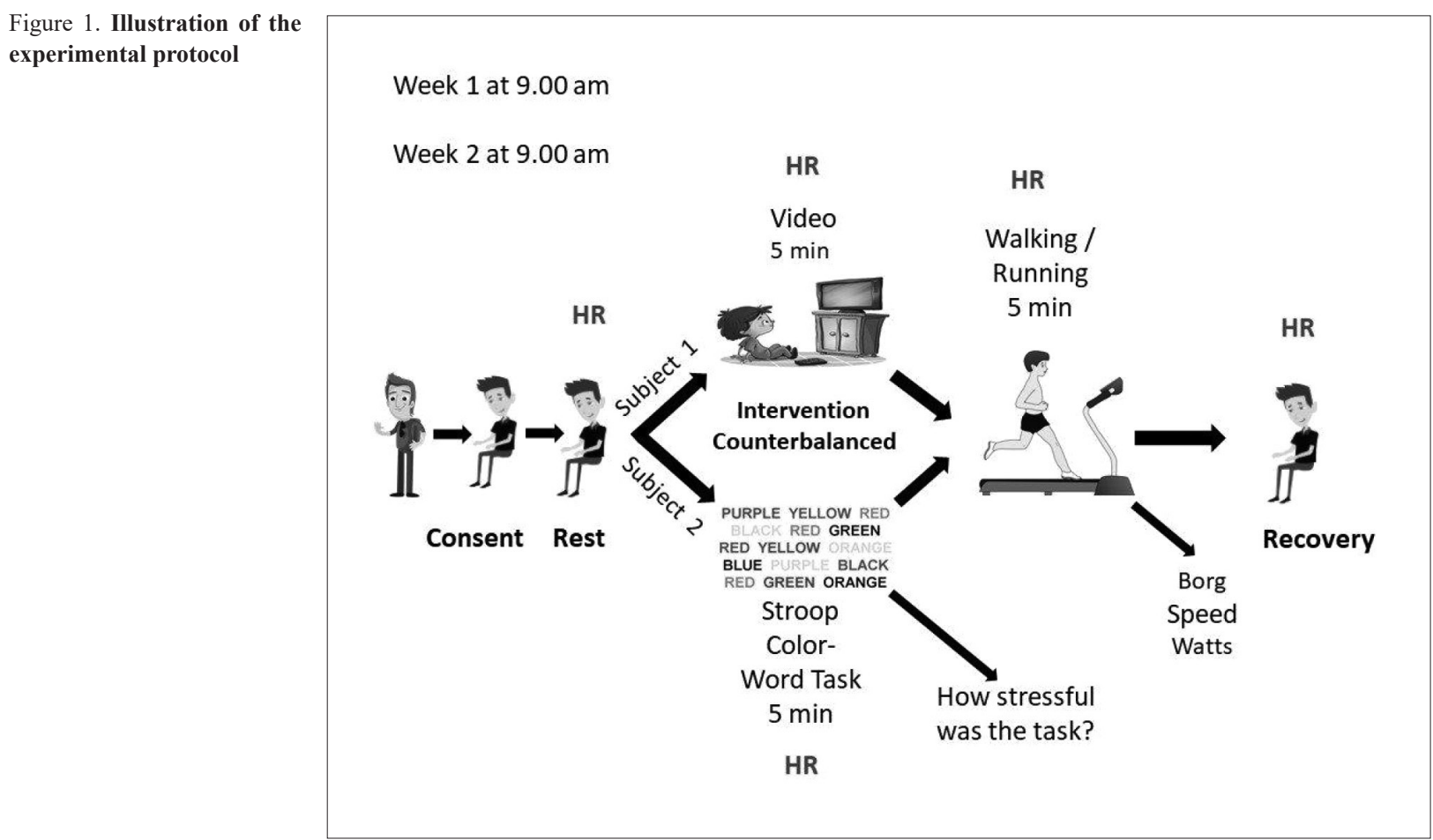

the control condition, participants watched a 5-min long video depicting the world's 10 tallest buildings (Metro World TV, 2018). Walking or jogging was performed on a H/P Cosmos LE200CE (Nußdorf Traunstein Germany) treadmill. Performance measures were obtained from its display. Heart rate was measured with a Polar H7 Bluetooth 4.0 smart chest band transmitter (Polar Electro Oy, Kempele, Finland). Exercise intensity, expressed as the percent $(\%)$ of maximal heart rate reserve (\%MHRR), was calculated with the Karvonen formula (She et al., 2014). Perceived effort was measured with the 10item version of the Borg scale (Borg, 1982). The perceived level of stress of the Stroop task was measured on a 10-point Likert scale ranging from 'not stressful at all' to 'very stressful'.

Procedure. After signing an informed consent form, participants rested for 5-min and baseline heart rate (HR) was recorded. Next, the odd-number participants watched a video while even-number participants were exposed to mental stress, both lasting for 5-min. One week later, these interventions were presented again in the reverse order to the participants. Following the interventions, participants walked or ran for 5-min at a self-selected pace on the treadmill. Their HR was continuously monitored and averaged for the stress/video and exercise sessions. After the selfpaced exercise, participants were asked to rest, and their recovery HR was recorded. The protocol is illustrated in Figure 1.

\section{RESULTS}

Participants rated the Stroop task as only moderately stressful $(M=5.07 \pm S D=2-07)$. Difference scores between baseline and exercise HR were calculated and correlated with the perceived stressfulness of the Stroop task. The correlation was statistically significant $\left(r=.474, p=.009, R^{2}=.23\right)$. The Greenhouse-Geisser corrected RMANOVA resulted in a statistically significant condition by time interaction $(\mathrm{F}[2.47,69.09]=12.90, p<.001$, effect size [Cohen's $d$ ] $=1.36$ ) for HR (see Figure 2). Participants' HRs were significantly higher during the stress versus control condition $(t$ [28] $=6.31$, $p<.001, d=-1.08,95 \%$ CI $[d]=-1.63$ to -0.52 ) and when exercising after stress versus video (control) condition $(t[28]=2.46, p=.02, d=-0.47$, $95 \%$ CI $[d]=-0.96$ to -0.09 ). The multivariate RMANOVA, examining the differences in perceived exertion, speed of the walk/run, energy expenditure and \%MHHR after the stress and control conditions, resulted in a statistically significant multivariate condition effect (Pillai's trace $=.340, F(4,25)=$ $3.22, p=.029$, partial Eta squared $\left.\left(\eta_{p}{ }^{2}\right)=.340\right)$. The univariate tests revealed that apart from perceived exertion, all exercise parameters were higher after the stress than the control session (Table). 
Figure 2. Heart rate profiles in two experimental conditions

Note. Statistically significant differences were observed in the stress/video and walk/run periods.

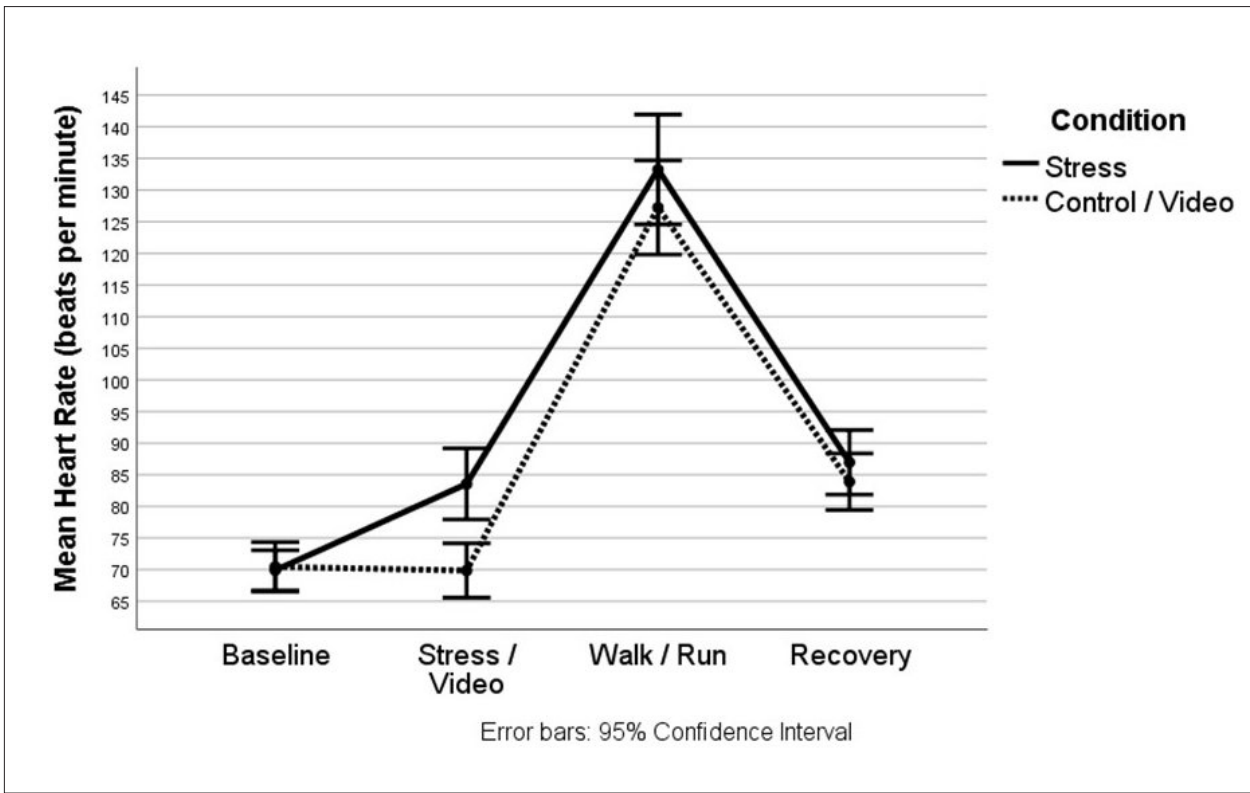

Table. Summary of the univariate tests $(d f=1,28)$ comparing perceived exertion and three exercise parameters after stress and control conditions

\begin{tabular}{|l|c|c|c|c|c|}
\hline Measure & M(SD) After Stroop & M(SD) After Video & F & p & $\begin{array}{c}\text { Effect size } \\
\left(\boldsymbol{\eta}_{p}^{2}\right)\end{array}$ \\
\hline Perceived exertion (Borg scale) & $3.66(1.11)$ & $3.69(1.26)$ & 0.015 & 0.904 & 0.001 \\
\hline $\begin{array}{l}\text { Speed of the walk and/or run } \\
\text { (km/h) }\end{array}$ & $8.51(2.48)$ & $7.37(2.62)$ & 9.885 & $\mathbf{0 . 0 0 4}$ & 0.261 \\
\hline Energy expenditure (Watts) & $278.34(107.90)$ & $240.10(93.20)$ & 5.570 & $\mathbf{0 . 0 2 5}$ & 0.166 \\
\hline Exercise intensity (\% of MHRR) & $104.81(20.50)$ & $99.92(17.09)$ & 6.386 & $\mathbf{0 . 0 1 7}$ & 0.186 \\
\hline
\end{tabular}

Note. $M$ - mean; $S D$ - Standard deviation; $\mathrm{km} / \mathrm{h}$ - kilometers per hour; $M H R R$ - maximal heart rate reserve; statistically significant results are in highlighted in bold.

\section{DISCUSSION}

The current study's results suggest the existence of a subliminal cathartic response even to a mild and artificial laboratory stressor. It is subliminal because the perceived exertion was not different between the two sessions, while all the performance measures differed significantly. The effect size of the difference between the stress and the control condition was large (i.e., $\eta_{p}{ }^{2}>0.14$; Cohen, 1988) in all measures. This finding is important because, despite the stressor's mild and artificial nature in this laboratory study, considerably meaningful effects have emerged. These effects followed the sympathetic activation, reflected by the increased heart rate, induced by the Stroop test. Thus, although the heart rate is only a crude index of sympathetic activity (Péronnet \& Szabo, 1993), the results suggest that the cathartic response surfaces after any stressor, which activates the sympathetic system or prepares the organism for the flight or fight response (Cannon, 1915). Our results agree with recent reports from non-exercise settings, such as cathartic response in swearing drivers (Popuşoi, G. M. Havârneanu, \& C. E. Havârneanu, 2018), ways of venting frustration at the workplace (Roeder, Garner, \& Carr, 2019), and playing aggressive video games (Lee, Kim, \& Choi, 2021).

In the context of physical effort, our results agree with the findings reported by Szabo and Tsang (2003). They also found the stressexposed group exercised with greater intensity 
than the control group without reporting greater subjectively perceived effort. However, the two studies differ in their design. Here we used a cross-over within-participants design, a different stressor, and a shorter exercise duration, which all could have contributed to a lower, but statistically significant and meaningful difference between the stress and control condition. An active stressor (one upon which the affected individual can act), such as the one used in the current work, usually elicits a greater sympathetic response than a passive stressor (such as the war images employed by Szabo and Tsang) over which the exposed person has no control (Bacon, Plourde, Paine, Cartier, \& Lavoie, 2018). Despite considerable differences, the study of Szabo and Tsang (2003) and the current research show that laboratory stressors, whether active or passive, generate a cathartic response characterized by greater (subconscious) physical work in contrast to a no-stress control condition. Finally, despite these two laboratory studies showing no difference in perceived exercise effort, and consequently suggesting a subliminal effect, the cathartic motive for exercise participation was ranked as third (out of eight; after fitness and health) in a large sample of young adults (Gut, J. Schmid, J. Schmid, \& Conzelmann, 2019). Based on the catharsis theory, people involved in contact sport-specific tasks may experience catharsis in getting rid of frustration/aggression (Huđin et al., 2020). However, the cathartic response is not limited to anger and aggression (Steckley, 2018). The here adopted Stroop test, and war images in Szabo's and Tsang's work might have induced stress encompassing other emotions, too. To get rid of them (i.e. "let off steam"), subconsciously, participants worked harder after stress than after the control session.

However, the stressors used in laboratory research were artificial (Péronnet \& Szabo, 1993) because they have no significant impact on the participant's' everyday life. Nonetheless, the stressresponse also occurred in this 'unnatural' situation because natural selection has not selected any specific response to laboratory stress. Therefore, the exposed organism 'borrowed' the vestigial response available for coping with a physical threat. In accord with Cannon (1915), real-life stressors could be expected to generate greater sympathetic activation or a stronger flight or fight response.
Consequently, the need for catharsis is likely to be amplified in real-life situations. However, this is a conjecture that needs empirical scrutiny.

Overall, the current results based on a mild stressor (rated only as moderate by the participants) elicited increased and noteworthy physical performance even during a low-intensity exercise. According to Borg (1982), a score below 4 (refer to Table) on the 0-10 scale reflects lowintensity activity. Thus, at this relatively low exercise level, objective differences in physical performance were evident, which, in agreement with Szabo's and Tsang's (2003) results, was not accompanied by a difference in perceived effort between the experimental and control condition. The link between stress and greater work during exercise is also justified by the significant positive correlation between the amount of increase in heart rate (i.e., difference from baseline) during the selfselected exercise and the level of perceived stress, which in the current study explained $23 \%$ of the variance between the two variables. Accordingly, the findings suggest that a mild artificial laboratory stressor can mobilize physical effort at a subliminal level. This result can most likely reflect the natural need for letting off steam that manifests itself in the form of a cathartic response.

Some of the current study's limitations include artificial stress, single-gender delimitation, young exercising, and volunteer participants. Future empirical studies, examining both genders and a wider age-range, and various stressors could yield results with a critical practical implication, which is to provide people with physical means to let off steam. Physical activity is perhaps the best therapeutic way of catharsis (Eliot, Forker, \& Robertson, 1976). Other, less approved initiatives also exist (Lee, 2020; Martin, 2016), but these have not received scholastic attention to date. Here we provide more evidence for a catharsis theory. People need to let off steam even after minor artificial stress. In some real-life stress situations, these subliminal needs might be amplified. Psychosocial stress could trigger the vestigial (physical) response that should be inhibited due to social norms. This inhibition might lead to morbidity (Miller \& O'Callaghan, 2002). Thus, stress that triggers increased sympathetic activity begs for physical energy release-dependent coping as reflected by the catharsis theory. 


\section{CONCLUSION}

The current within-participants cross-over laboratory research suggests that the increased arousal, manifested by elevated heart rate measures, caused by an artificial stressor was "carried over" into the walk or jog exercise period. This residual sympathetic response (to stress) prompted participants to exercise harder in the experimentalthan in the no-stress control session. However, they did not perceive the difference in the exerted effort in the two laboratory sessions. This finding suggests that they had more available energy (a surplus) due to the increased arousal, which made them unaware that they exert more effort than in the control session. The magnitude of change in heart rate correlated positively with the perceived stress. Overall, the results suggest that a 'flight or fight' response to psychosocial stress emerges in the form of subliminal catharsis. This cathartic manifestation is a "natural" evolutionary response to the stress-related activation of the vegetative nervous system that begs for physical forms of coping in psychosocial stress situations.

Conflict of interest: The authors have no conflict of interest to declare.

\section{REFERENCES}

Bacon, S., Plourde, A., Paine, N., Cartier, A., \& Lavoie, K. (2018). Impact of acute active and passive stress on physiological responses in adults with asthma. European Respiratory Journal, 52, PA654. https://doi. org/10.1183/13993003.congress-2018.pa654

Borg, G. A. V. (1982). Psychophysical bases of perceived exertion. Medicine \& Science in Sports \& Exercise, 14(5), 377-381. https://doi.org/10.1249/00005768198205000-00012

Boutcher, Y. N., \& Boutcher, S. H. (2006). Cardiovascular response to Stroop: Effect of verbal response and task difficulty. Biological Psychology, 73(3), 235-241. https://doi.org/10.1016/j.biopsycho.2006.04.005

Brown, T. G., Szabo, A., \& Seraganian, P. (1988). physical versus psychological determinants of heart rate reactivity to mental arithmetic. Psychophysiology, 25(5), 532-537. https://doi.org/10.1111/j.1469-8986.1988. tb01888.x

Cannon, W. B. (1915). Bodily changes in pain, hunger, fear and rage: An account of recent researches into the function of emotional excitement. New York, NY: D. Appleton \& Company. https://doi.org/10.1037/ 10013-000

Cohen, J. (1988). Statistical power analysis for the behavioral sciences (2nd ed.). Hillsdale, NJ: Erlbaum. http://www.utstat.toronto.edu/ brunner/ oldclass/378f16/readings/CohenPower.pdf

Egorov, A. Y., \& Szabo, A. (2013). The exercise paradox: An interactional model for a clearer conceptualization of exercise addiction. Journal of Behavioral Addictions, 2(4), 199-208. https://doi.org/10.1556/jba.2.2013.4.2

Eliot, R. S., Forker, A. D., \& Robertson, R. J. (1976). Aerobic exercise as a therapeutic modality in the relief of stress (pp. 231-242). In Manninen V. \& Halonen P. I. (Eds). Physical Activity and Coronary Heart Disease. 3rd Paavo Nurmi Symposium, Helsinki, September 1975. Advances in Cardiology, 18, Basel, Karger. https:// doi.org/10.1159/000399527
Faul, F., Erdfelder, E., Buchner, A., \& Lang, A.-G. (2009). Statistical power analyses using G*Power 3.1: Tests for correlation and regression analyses. Behavior Research Methods, 41(4), 1149-1160. https://doi. org/10.3758/brm.41.4.1149

Gut, V., Schmid, J., Schmid, J., \& Conzelmann, A. (2019). The Bernese Motive and Goal Inventory for Adolescence and Young Adulthood. Frontiers in Psychology, 9. https://doi.org/10.3389/fpsyg.2018.02785

Huđin, N., Glavaš, D., \& Pandžić, M. (2020). Contact sports as a sport of more aggressive athletes? Aggressiveness and other psychological characteristics of youth athletes involved in contact and non-contact sports. TIMS. Acta, 14(1), 5-16. https://doi.org/10.5937/ timsact14-27343

Karthikeyan, P., Murugappan, M., \& Yaacob, S. (2011). A review on stress inducement stimuli for assessing human stress using physiological signals. 2011 IEEE 7th International Colloquium on Signal Processing and Its Applications. https://doi.org/10.1109/ cspa.2011.5759914

Lee, D. (2020). Raging with things: Performance of smashing at rage rooms (Doctoral dissertation). State University of New York at Buffalo. https://search.proquest. com/docview/2384861056?pq-origsite $=$ gscholar

Lee, E.-J., Kim, H. S., \& Choi, S. (2021). Violent video games and aggression: Stimulation or catharsis or both? Cyberpsychology, Behavior, and Social Networking, 24(1), 41-47. https://doi.org/10.1089/cyber.2020.0033

Martin, C. (2016). Anger rooms: A smashing new way to relieve stress. The New York Times, November 26, 2016. https://www.nytimes.com/2016/11/26/business/angerrooms-a-smashing-new-way-to-relieve-stress.html

McEwen, B. S. (1998). Protective and damaging effects of stress mediators. New England Journal of Medicine, 338(3), 171-179. https://www.nejm.org/doi/ full/10.1056/NEJM199801153380307 
Metro World TV (2018). Top 10 Tallest Building In The World 2018. Retrieved from https://www.youtube.com/ watch? $\mathrm{v}=\mathrm{mGTrbLqD} \_\mathrm{S} 0 \& \mathrm{t}=200 \mathrm{~s}$

Miller, D. B., \& O'Callaghan, J. P.(2002). Neuroendocrine aspects of the response to stress. Metabolism, 51(6), 5-10. https://doi.org/10.1053/meta.2002.33184

Peronnet, F., \& Szabo, A. (1993). Sympathetic response to acute psychosocial stressors in humans: linkage to physical exercise and training. In P. Seraganian (Ed.), Exercise psychology: The influence of physical exercise on psychological processes (pp. 172-217). New York: Wiley. https:// www.wiley.com/en-us/Exercise+Psychology $\% 3 \mathrm{~A}+\mathrm{The}+\mathrm{I}$ nfluence + of + Physical + Exercise + on + Psychological + Proc esses-p-9780471527015

Popuşoi, S. A., Havârneanu, G. M., \& Havârneanu, C. E. (2018). "Get the $\mathrm{f} \# * \mathrm{k}$ out of my way!" Exploring the cathartic effect of swear words in coping with driving anger. Transportation Research Part F: Traffic Psychology and Behaviour, 56, 215-226. https://doi. org/10.1016/j.trf.2018.04.013

Roeder, A. C., Garner, J. T., \& Carr, K. (2019). Workplace Relationships, Stress, and Verbal Rumination in Organizations. Southern Communication Journal, 85(2), 63-72. https://doi.org/10.1080/1041794x.2019.1697893

She, J., Nakamura, H., Makino, K., Ohyama, Y., \& Hashimoto, H. (2014). Selection of suitable maximumheart-rate formulas for use with Karvonen formula to calculate exercise intensity. International Journal of
Automation and Computing, 12(1), 62-69. https://doi. org/10.1007/s11633-014-0824-3

Sosnowski, T., Nurzynska, M., \& Polec, M. (1991). Active-passive coping and skin conductance and heart rate changes. Psychophysiology, 28(6), 665-672. https:// doi.org/10.1111/j.1469-8986.1991.tb01011.x

Steckley, L. (2018). Catharsis, containment and physical restraint in residential child care. The British Journal of Social Work, 48(6), 1645-1663. https://doi.org/10.1093/ bjsw/bcx131

Stroop, J. R. (1935). Studies of interference in serial verbal reactions. Journal of Experimental Psychology, 18, 643-662. https://pure.mpg.de/rest/items/item_2389918/ component/file_2389917/content

Szabo, A., \& Tsang, E. (2003). Motivation for increased self-selected exercise intensity following psychological distress: Laboratory-based evidence for catharsis? Journal of Psychosomatic Research, 55(2), 133. https:// doi.org/10.1016/s0022-3999(03)00308-8

Walter, N., \& Heinen, T. (2019). Exercise addiction and its relation to psycho-social aspects and motives. Problems of Psychology in the 21st Century, 13(2), 113126. https://doi.org/10.33225/ppc/19.13.113

World Medical Association. (2019). WMA Declaration of Helsinki-ethical principles for medical research involving human subjects. July 9, 2018. Retrieved from https://www. wma.net/policies-post/wma-declaration-of-helsinki-ethicalprinciples-for-medical-research-involving-human-subjects/ 